\title{
Enhancement of lignocellulosic degradation in high-moisture alfalfa via anaerobic bioprocess of engineered Lactococcus lactis with the function of secreting cellulase
}

Qinhua Liu, Junfeng Li, Jie Zhao, Jingxing Wu and Tao Shao*

\begin{abstract}
Background: Butyric fermentation and a substantial loss of dry matter (DM) often occur in alfalfa silage during the rainy season, which is not conducive to subsequent biofuel production. Currently, there have been negative effects on the combination of cellulases and lactic acid bacteria (LAB) on processing high-moisture alfalfa silage; however, transgenically engineered LAB strains that secrete cellulase have been proposed as an alternative approach to avoid the above problem. The objective of the present study was to construct engineered Lactococcus lactis strains with high-efficiency secretory-expressing cellulase genes from Trichoderma reesei and to investigate the effects of the combination of transgenically engineered L. lactis strains HT1/pMG36e-usp45-bg/1, HT1/pMG36e-usp45-cbh2, and HT1/pMG36e-usp45-eg/3 (HT2) on fermentation quality, structural carbohydrate degradability and nonstructural carbohydrate fermentation kinetics of high-moisture alfalfa silage treated without additive as a negative control (Control), or/and with cellulase (EN), wild-type L. lactis subsp. lactis MG1363 (HT1) and the combination of HT1 and EN $(\mathrm{HT} 1+\mathrm{EN})$ as positive additive controls.
\end{abstract}

Results: Engineered L. lactis strains were successfully constructed and efficiently secreted endoglucanase (1118 mU/ $\mathrm{mL})$, cellobiohydrolase $(222 \mathrm{mU} / \mathrm{mL})$, and $\beta$-glucosidase $(131 \mathrm{mU} / \mathrm{mL})$ and had high filter paper activity $(236 \mathrm{mU} / \mathrm{mL})$. Ensiling experiments verified that HT2 obtained the highest fermentation quality score (83.6) and most efficiently processed high-moisture alfalfa silage, demonstrated by a low pH (4.49) and ammonia-N content (106 g/kg nitrogen) and a high lactic acid content (67.1 $\mathrm{g} / \mathrm{kg}$ DM) and without butyric acid. Change curves of structural carbohydrates revealed that HT2 degraded more lignocelluloses, demonstrated by the lowest contents of neutral detergent fibre, acid detergent fibre, cellulose and hemicellulose after ensiling for 60 days. Kinetic analysis showed that the most residual water-soluble carbohydrates, glucose, fructose and xylose generated by lignocellulose degradation were produced by HT2, followed by HT1 + EN. The HT2-treated silages had the highest DM recovery, had the fewest Clostridia spores, emitted a fragrance and were not sticky.

Conclusion: HT2 improved the conversion of lignocellulose to sugars and processed high-moisture alfalfa silage efficiently. This is a novel strategy that can be used to enhance lignocellulosic degradation in high-moisture alfalfa via a bioprocess with transgenically engineered L. lactis strains, which could enhance the development of alfalfa as a biomass feedstock and promote second-generation biofuel development in the rainy season.

Keywords: Cellulase, Ensiling, Lactococcus lactis, Lignocellulose

*Correspondence: taoshaolan@163.com

Institute of Ensiling and Processing of Grass, Nanjing Agricultural

University, Weigang 1, Nanjing 210095, China 


\section{Background}

The substitution of petroleum with renewable biomass feedstock for the production of chemicals and biofuel as a method to reduce greenhouse gas emissions and increase energy security has been given considerable attention [1]. Alfalfa is rich in protein, is widely used as animal feed and is also a good candidate feedstock for biofuel production [2].

Ensiling is a bioprocessing method for the anaerobic preservation and pretreatment of lignocellulosic biomass to produce feed and biofuel $[3,4]$. However, alfalfa contains low contents of dry matter (DM) and water-soluble carbohydrates (WSC), especially in the rainy season, and has a high buffer capacity that often causes increased butyric acid and substantial DM loss [5]. The few nutrients in poor-quality alfalfa silage are not only useless for feeding animals but also decrease biofuel production due to insufficient soluble nonstructural carbohydrates, which deliver energy sources to yeast for producing bioethanol [6]. Moreover, high butyric acid concentration in poor-quality silage can restrain the growth of yeast [7]. Therefore, in the rainy season, maximally preserving high-moisture alfalfa via the ensiling bioprocess is an interesting and potential strategy for subsequent biofuel production.

Traditional methods for enhancing ensiling forage are wilting and adding acids, cellulase and lactic acid bacteria (LAB) alone or combined [5]. However, wilting alfalfa cannot be used in the rainy season, e.g., the plum rain season (from late spring to summer) in East China, and the enlarged cost and corrosivity are the disadvantages of using acids to ensile alfalfa [8]. Adding cellulase or $\mathrm{LAB}$ alone or the combination of cellulase and $\mathrm{LAB}$ have positive effects on improving lignocellulosic degradation and fermentation quality and reducing DM loss in many kinds of silages [9-11], but previous studies have described negative effects of the combined treatment of cellulase and LAB on alfalfa silage. Lynch et al. found that adding EN or LAB alone or combined did not affect DM losses or lactic and acetic acid contents of alfalfa silage compared with the control after ensiling for 70 days [12]. Kozelov et al. found that adding cellulase or LAB alone or combined had no effects on decreasing the contents of neutral detergent fibre (NDF) and non-fibre carbohydrates in high-moisture alfalfa silage; as a result, the silage had a high $\mathrm{pH}(>5.0)$ after ensiling for 60 days [13]. The proposed explanation is that high-moisture alfalfa contains few WSC, some cellulases cannot degrade lignocellulose of alfalfa [12], or some lignocellulose degradation products of cellulase cannot be fermented by LAB $[14,15]$, e.g., high-molecular-weight oligosaccharides. Therefore, cellulase degrades lignocellulose into sufficient substrates which can be utilized by LAB to preserve high-moisture alfalfa as a biomass feedstock.

Trichoderma reesei is known as a potent cellulase producer because of its excellent genes that encode secreted cellulases, mainly endoglucanases, cellobiohydrolases and $\beta$-glucosidases [16], and the effective function of its cellulases to degrade lignocellulose into substrates utilizable by LAB during ensiling, as shown in our previous studies $[17,18]$. To date, transgenic technology has allowed the expression of the endoglucanase gene of T. reesei in Escherichia coli to increase the level of expression of the endoglucanase gene using an inducible expression system, pET22b, and directed evolution $[16,19]$. However, the total enzyme yields of recombinant $E$. coli were lower than the yields when using the signal peptide of Usp45 (usp45) derived from L. lactis and a pMG36e plasmid in E. coli $(761 \mathrm{U} / \mathrm{L})$ and L. lactis $(1879 \mathrm{U} / \mathrm{L})$, as described in our previous study [20]. One report concluded that usp 45 could enhance secretion to increase heterologous protein production in L. lactis [21]. However, heterogeneous protein secretion in L. lactis using usp 45 and pMG36e depends on many factors, e.g., the heterogenous protein size, conformation, and solubility [21-23]. The bigger size of cellobiohydrolase and $\beta$-glucosidase and their different conformations and solubilities from endoglucanase may hinder their secretion in L. lactis using usp45 and pMG36e. To date, little information is available on the successful expression of the cellobiohydrolase and $\beta$-glucosidase genes of $T$. ree$s e i$ in LAB using the pMG36e plasmid and usp 45. Therefore, clarifying the feasibility of successfully constructing transgenically engineered LAB that secrete endoglucanase, cellobiohydrolase and $\beta$-glucosidase using the pMG36e plasmid and usp 45 benefits second-generation biofuel development, because it is increasingly dependent on the extracellular expression of cellulases [24]. Their application in ensiling may produce lignocellulose degradation products utilizable by $L$. lactis to promote lactic fermentation and provide an opportunity to better develop alfalfa as an alternative biomass feedstock for second-generation biofuel development in the rainy season.

The aim of this study was to construct transgenically engineered $L$. lactis strains that secrete endoglucanase, cellobiohydrolase, and $\beta$-glucosidase by a simple and highly efficient secretory expression method and investigate the effect of the combination of transgenically engineered L. lactis strains HT1/pMG36e-usp45-bgl1, HT1/pMG36e-usp45-cbh2, and HT1/pMG36e-usp45egl3 (HT2) on processing high-moisture alfalfa as biomass feedstock via the evaluation of fermentation quality, structural carbohydrate degradability and nonstructural carbohydrate fermentation kinetics, using no additive 
as a negative control (Control), and cellulase (EN), wildtype L. lactis subsp. lactis MG1363 (HT1) and the combination of $\mathrm{HT} 1$ and $\mathrm{EN}(\mathrm{HT} 1+\mathrm{EN})$ as positive additive controls.

\section{Methods}

\section{Bacterial strains, plasmids and culture conditions}

The bacterial strains and plasmids used in this study are listed in Table 1. Escherichia coli DH5 $\alpha$ (DH5 $\alpha$ ) was cultured in Luria-Bertani medium (both agar and broth) at $37{ }^{\circ} \mathrm{C}$, and HT1 was grown in M17 broth (Oxoid
Ltd., Shanghai, China) supplemented with $5 \mathrm{~g} / \mathrm{L}$ glucose (GM17) at $30{ }^{\circ} \mathrm{C}$. A total of $300 \mu \mathrm{g} / \mathrm{mL}$ of erythromycin (Takara Biotechnology Co., Ltd., Dalian, China) was used to screen the positive $\mathrm{DH} 5 \alpha$ recombinants containing the pMG36e backbone, and $5 \mu \mathrm{g} / \mathrm{mL}$ of erythromycin was used to screen the positive recombinant HT1 containing the pMG36e backbone. $40 \mu \mathrm{g} / \mathrm{mL}$ of ampicillin (TakaRa Biotechnology Co., Ltd., Dalian, China) and $4 \mu \mathrm{L}$ of $100 \mathrm{mg} / \mathrm{mL}$ IPTG (isopropyl $\beta$-D-1thiogalactopyranoside) (TakaRa Biotechnology Co., Ltd., Dalian, China) were plated on agar to screen for the

Table 1 Bacterial strains and plasmids used in this study

\begin{tabular}{|c|c|c|}
\hline Strain and plasmid & Relevant trait(s) & Source or reference \\
\hline \multicolumn{3}{|l|}{ Strains } \\
\hline Escherichia coli DH5a & $\begin{array}{l}\text { supE44 } \triangle \text { lac U169 (Ф80 lacZ } \triangle M 15) \text { hsdR17 recA1, endA1 gyrA96 } \\
\text { thi-I relA1 }\end{array}$ & This laboratory \\
\hline Lactococcus lactis subsp. lactis MG1363 & $\begin{array}{l}\text { A plasmid-free derivative of NCD0712; source of usp45; ADT } \\
\text { indicator }\end{array}$ & This laboratory \\
\hline Trichoderma reesei 3.3711 & Type culture & $\begin{array}{l}\text { China General Microbio- } \\
\text { logical Culture Collection } \\
\text { Center }\end{array}$ \\
\hline E. coli DH5a/pMG36e & E. coli DH5a with pMG36e & This study \\
\hline E. coli DH5a/pMG36e-bg/1 & E. coli DH5a with pMG36e-bg/1 & This study \\
\hline E. coli DH5a/pMG36e-cbh2 & E. coli DH5a with pMG36e-cbh2 & This study \\
\hline E. coli DH5a/pMG36e-eg/3 & E. coli DH5a with pMG36e-eg/3 & This study \\
\hline E. coli DH5a/pMG36e-usp45-bg/1 & E. coli DH5a with pMG36e-usp45-bg/1 & This study \\
\hline E. coli DH5a/pMG36e-usp45-cbh2 & E. coli DH5a with pMG36e-usp45-cbh2 & This study \\
\hline E. coli DH5a/pMG36e-usp45-eg/3 & E. coli DH5a with pMG36e-usp45-eg/3 & This study \\
\hline E. coli DH5a/pMD18-T-usp45-bg/1 & E. coli DH5a with pMD18-T-usp45-bg/1 & This study \\
\hline E. coli DH5a/pMD18-T-usp45-cbh2 & E. coli DH5a with pMD18-T-usp45-cbh2 & This study \\
\hline E. coli DH5a/pMD18-T-usp45-eg/3 & E. coli DH5a with pMD18-T-usp45-eg/3 & This study \\
\hline L. lactis subsp. lactis MG1363/pMG36e & L. lactis subsp. lactis MG1363 with pMG36e & This study \\
\hline L. lactis subsp. lactis MG1363/pMG36e-bg/1 & L. lactis subsp. lactis MG1363 with pMG36e-bg/1 & This study \\
\hline L. lactis subsp. lactis MG1363/pMG36e-cbh2 & L. lactis subsp. lactis MG1363 with pMG36e-cbh2 & This study \\
\hline L. lactis subsp. lactis MG1363/pMG36e-eg/3 & L. lactis subsp. lactis MG1363 with pMG36e-eg/3 & This study \\
\hline L. lactis subsp. lactis MG1363/pMG36e-usp45-bg/1 & L. lactis subsp. lactis MG1363 with pMG36e-usp45-bg/1 & This study \\
\hline L. lactis subsp. lactis MG1363/pMG36e-usp45-cbh2 & L. lactis subsp. lactis MG1363 with pMG36e-usp45-cbh2 & This study \\
\hline L. lactis subsp. lactis MG1363/pMG36e-usp45-eg/3 & L. lactis subsp. lactis MG1363 with pMG36e-usp45-eg/3 & This study \\
\hline \multicolumn{3}{|l|}{ Plasmids } \\
\hline pMD18-T & $A m p^{r}$ & Takara Biotechnology Co., Ltd. \\
\hline pMD18-T-usp45-bg/1 & Amp ${ }^{r}$, clone usp45-bg/1 fusion gene & This study \\
\hline pMD18-T-usp45-cbh2 & Amp', clone usp45-cbh2 fusion gene & This study \\
\hline pMD18-T-usp45-eg/3 & Ampr', clone usp45-eg/3 fusion gene & This study \\
\hline pMG36e & $\begin{array}{l}\text { Emr ; expression vector with the P32 promoter, multiple cloning } \\
\text { sites (MCF) and prtP translational terminator }\end{array}$ & Liu et al. [20] \\
\hline pMG36e-bg/1 & Emr; expression of bg/1 & This study \\
\hline pMG36e-cbh2 & Em; expression of $c b h 2$ & This study \\
\hline pMG36e-eg/3 & Emr; expression of eg/3 & This study \\
\hline pMG36e-usp45-bg/1 & Emr, secretory expression of $b g / 1$ & This study \\
\hline pMG36e-usp45-cbh2 & $E m^{r}$, secretory expression of $c b h 2$ & This study \\
\hline pMG36e-usp45-eg/3 & $\mathrm{Em}^{\mathrm{r}}$, secretory expression of eg/3 & This study \\
\hline
\end{tabular}


positive DH5 $\alpha$ recombinants containing the pMD18-T backbone. T. reesei 3.3711 (China General Microbiological Culture Collection Center) was cultured in potato dextrose broth or agar (Nissui-seiyaku Ltd., Tokyo, Japan) medium at $30{ }^{\circ} \mathrm{C}$ for $72 \mathrm{~h}$. The experiment was carried out according to the schematic (Fig. 1).

\section{Construction and examination of fusion genes}

RNA was extracted from $T$. reesei 3.3711 with an E.Z.N.A. ${ }^{\mathrm{TM}}$ Fungal RNA Kit (Omega Bio-tek, Inc., Shanghai, China), and cDNA was obtained using a First-Strand cDNA Synthesis Kit (Omega Bio-tek, Inc., Shanghai, China). Primer P1 with EcoRI (5'-TTGAATTCCGTTGT ACCTCCTGCAGGGACTC-3') and primer P2 with BamHI (5'-TTCGGATCCGCTACCGACAGAGTGCTC GTCAG-3') were designed according to the bgll gene sequence (GenBank Accession No. U09580.1) and were used to amplify the $\beta$-glucosidase catalytic domains of the $b g l 1$ gene without the signal peptide and intron fragments (2139 bp). Polymerase chain reaction (PCR) was performed with a total volume of $25 \mu \mathrm{L}$ containing 12.5 $\mu \mathrm{L}$ of $2 \times$ PrimeSTAR Max DNA polymerase (TakaRa Biotechnology Co., Ltd., Dalian, China), $1 \mu \mathrm{L}$ cDNA and $1 \mu \mathrm{L}$ of each primer. The PCR program was as follows: pre-denaturation at $94{ }^{\circ} \mathrm{C}$ for $5 \mathrm{~min}$, followed by 30 cycles consisting of denaturation at $98{ }^{\circ} \mathrm{C}$ for $15 \mathrm{~s}$, annealing at $55^{\circ} \mathrm{C}$ for $15 \mathrm{~s}$, extension at $72{ }^{\circ} \mathrm{C}$ for $4 \mathrm{~min}$, and final elongation at $72{ }^{\circ} \mathrm{C}$ for $10 \mathrm{~min}$. The fusion gene, usp 45-egl3, was constructed with the same methods described in our previous study [20]. The correct $b g l 1$ gene fragment was linked with usp 45 (81 bp) of HT1 using the overlapping extension PCR method, and the restriction enzyme sequences were removed by a company (Nanjing Genebay Biotech Co., Ltd., Nanjing, China). The CD region of the $c b h 2$ gene (GenBank Accession No. M55080.1) without a fraction of its signal peptide was also linked with usp45 (81 bp) of HT1 using the overlapping extension PCR method from a company (Shanghai Generay Biotech Co., Ltd., Shanghai, China). The fusion genes usp45-bgl1, usp 45-cbh2, and usp 45-egl3 were cloned into pMD18-T and sequenced. The sequences of the fusion genes were BLAST searched with reference genes in NCBI.

\section{Construction and transformation of recombinant plasmid}

The corrected pMD18-T vector containing fusion genes and pMG36e were digested with the appropriate restriction enzymes in our laboratory. The fusion gene fragments and the digested pMG36e were linked via T4-DNA ligase (TakaRa Biotechnology Co., Ltd. Dalian, China) to produce the recombinant vectors pMG36eusp45-bgl1, pMG36e-usp45-cbh2, and pMG36e-usp45egl3. Then, the recombinant vectors were introduced into DH5 $\alpha$ using a standard $\mathrm{CaCl}_{2}$ transformation method
[25], and transformed into HT1 via electroporation using an Eppendorf multiporator (Eppendorf AG, Hamburg, Germany) [26], at a pulse voltage of $2.15 \mathrm{kV}$ and a pulse time of $4.8 \mathrm{~ms}$.

\section{Screening and identification of positive clones}

Positive DH5 $\alpha /$ pMD18-T-usp45-bgl1, DH5 $\alpha /$ pMD18T-usp45-cbh2, and DH5 $\alpha$ /pMD18-T-usp45egl3 transformants were screened via the white colour of the clones. Positive DH $5 \alpha /$ pMG36e-usp $45-b g l 1$, DH5 $\alpha /$ pMG36e-usp 45-cbh2, DH5 $\alpha /$ pMG36e-usp 45egl3, HT1/pMG36e-usp45-bgl1, HT1/pMG36e-usp45cbh 2 and HT1/pMG36e-usp 45-egl3 transformants were screened via erythromycin selection. pMD18-T-usp45egl3 and pMG36e-usp45-egl3 were identified via the Sma I and Xba I digestion method. pMD18-T-usp45cbh2, pMG36e-usp45-cbh2, pMD18-T-usp 45-bgl1 and pMG36e-usp45-bgl1 were identified via the Sma I and Sph I digestion method. After digestion, the low-molecular-weight fragment was extracted using a Gel Extraction Mini Kit (Omega Bio-tek, Inc., Shanghai, China), which was sequenced and BLAST searched with reference genes in NCBI.

GM17 plates containing $5 \mathrm{~g} / \mathrm{L}$ of carboxymethyl cellulose $(\mathrm{CMC})$ and $5 \mu \mathrm{g} / \mathrm{mL}$ of erythromycin $(\mathrm{pH} 7.0)$ were used to screen the positive HT1/pMG36e-usp45-bgl1, HT1/pMG36e-usp45-cbh2 and HT1/pMG36e-usp45egl3 recombinants after culturing for $48 \mathrm{~h}$ at $30{ }^{\circ} \mathrm{C}$. The plates were then exposed to $1 \mathrm{~g} / \mathrm{L}$ Congo red solution. After incubation for $30 \mathrm{~min}$, the plates were washed with $1 \mathrm{~mol} / \mathrm{L} \mathrm{NaCl}$ to reveal the clear zones against a red background that developed via hydrolysis of CMC. The plates were rinsed with $5 \mathrm{~g} / \mathrm{L}$ acetic acid to maximally delineate the zones of clearing.

\section{Enzyme assays and protein analysis of recombinant $L$. lactis} According to the procedure in Biofuels: Methods and Protocols written by Mielenz [27], the maximum secretory activities of HT1/pMG36e-usp45-bgl1, HT1/pMG36e-usp45-cbh2, and HT1/pMG36e-usp45egl3 were individually detected using cellobiose, avicel and CMC. The filter paper activity of the recombinants when combined was detected using Whatman No. 1 filter paper as the substrate. One unit of activity was defined as the amount of enzyme that produced $1 \mu \mathrm{mol}$ of reducing sugar per minute in glucose equivalents and the enzyme activity was assayed in triplicate. The molecular masses of intracellular and extracellular enzymes of recombinant HT1/pMG36e-usp45-bgl1, HT1/pMG36e-usp45-cbh2 and HT1/pMG36e-usp45-egl3 were estimated via sodium dodecyl sulphate-polyacrylamide gel electrophoresis (SDS-PAGE) as described in our previous study [20]. 


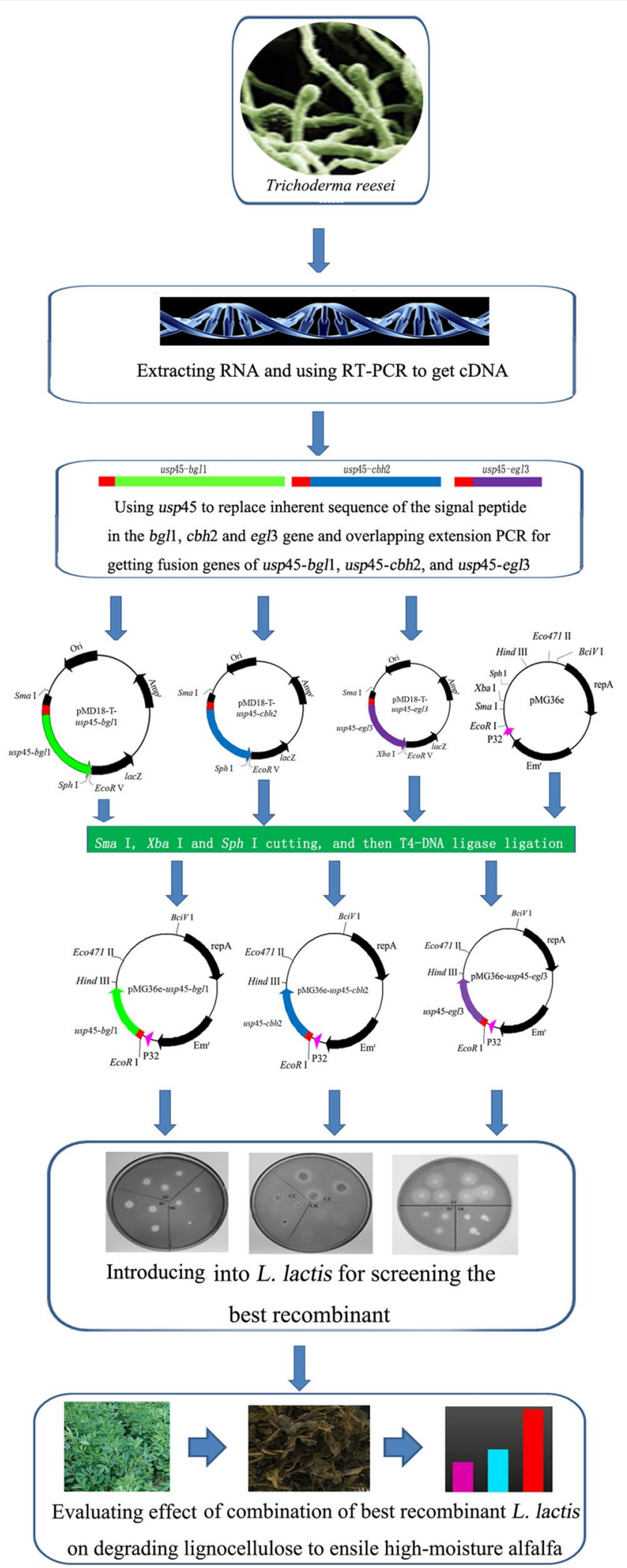

Fig. 1 Experimental schematic 


\section{Recombinants ensiling alfalfa}

Alfalfa was planted on September 20, 2015, in ten different fields (humid subtropical climate, latitude $32^{\circ} 01^{\prime} 59.81^{\prime \prime} \mathrm{N}$, longitude $118^{\circ} 50^{\prime} 13.63^{\prime \prime} \mathrm{E}$, altitude above sea level $17 \mathrm{~m}$ ) of Nanjing Agricultural University (Nanjing, China). The area of each field was $100 \mathrm{~m}^{2}$. The alfalfa was at the early flowering stage on May 11, 2016, and was harvested for making silage, immediately. Fresh alfalfa was chopped into 1 - to 2 -cm-long pieces by a forage chopper (Sh-2000, Shanghai Donxe Industrial Co., Ltd., Shanghai, China). Prior to ensiling, the alfalfa had a DM of $221 \mathrm{~g} / \mathrm{kg}$ fresh matter, a $\mathrm{pH}$ value of 6.28 and a buffering capacity of $244 \mathrm{mEq} / \mathrm{kg}$ DM. The composition of structural carbohydrates was $441 \mathrm{~g}$ for neutral detergent fibre (NDF)/ $\mathrm{kg} \mathrm{DM}, 326 \mathrm{~g}$ for acid detergent fibre (ADF) $/ \mathrm{kg} \mathrm{DM}$, and $84.3 \mathrm{~g} / \mathrm{kg}$ DM for acid detergent lignin (ADL). The total WSC content was $52.82 \mathrm{~g} / \mathrm{kg} \mathrm{DM}$, while the fraction of the individual soluble carbohydrates $(\mathrm{g} / \mathrm{kg} \mathrm{DM})$ was as follows: glucose (5.81), fructose (5.04), and xylose (5.68). The epiphytic lactic acid bacteria (LAB, $3.93 \mathrm{lg} \mathrm{cfu} / \mathrm{g}$ FM) on the alfalfa was less than aerobic bacteria (7.36 $\lg \mathrm{cfu} / \mathrm{g}$ FM) and yeast (4.98 $\mathrm{lg} \mathrm{cfu} / \mathrm{g}$ FM) and the fermentation efficiency (23.8) was lower than 35.

The strains HT1, HT1/pMG36e-usp45-bgl1, HT1/pMG36e-usp45-cbh2 and HT1/pMG36e-usp45egl3 were used after being cultured in GM17 broth at $30{ }^{\circ} \mathrm{C}$ for $30 \mathrm{~h}$. HT2 consisted of HT1/pMG36e-usp 45bgl1, HT1/pMG36e-usp 45-cbh2 and HT1/pMG36eusp 45-egl3 at an equal ratio (1:1:1). EN derived from Trichoderma reesei was purchased from a company (Rueyang Biotechnology Co., Ltd, Wuxi, China). The activity of EN was measured: cellulase 50,000 U/g.

Alfalfa obtained from 8 random fields was mixed into a pile and then was separated into 80 piles in the laboratory. The 80 piles ( 720 g per pile) were randomly ensiled with 5 additive treatments (without additive as the Control, and with EN, HT1, HT1+EN or HT2). The 16 piles per additive treatment were separately filled into 16 experimental silos (polyvinyl chloride bottle, $1 \mathrm{~L}$ ) immediately. According to McFarland turbidity standards, adjusted HT1 and HT2 were separately added to make the inoculation $1 \times 10^{6}$ colony-forming units (cfu) $/ \mathrm{g}$ fresh matter (FM). EN was added at $2 \mathrm{~g} / \mathrm{kg}$ of FM. EN was mixed with adjusted HT1 as HT1 + EN (dose at $2 \mathrm{~g} / \mathrm{kg} \mathrm{EN}+1 \times 10^{6} \mathrm{cfu} / \mathrm{g}$ HT1 of FM). The control was sprayed with the same amount of distilled water alone. The 80 silos were sealed using the same method described in the report of Liu et al. [28]. Four silos of each additive treatment were randomly selected and opened after ensiling at ambient temperature (23$37^{\circ} \mathrm{C}$ ) for $1,6,18$ and 60 days.

\section{Microbiological and chemical analysis}

$\mathrm{LAB}$, aerobic bacteria and yeast were counted according to the method described by Liu et al. [28]. Clostridial spores were enumerated by surface plating on supplemented Reinforced Clostridium Agar (Product Code: HB0316; Hopebio Co., Ltd., Qingdao, China) and anaerobic incubation for 3 days at $37^{\circ} \mathrm{C}$ according to the method described by Jonsson [29]. Fifty grams of alfalfa material was mixed with $200 \mathrm{~mL}$ of distilled water, and stored at $4{ }^{\circ} \mathrm{C}$ for $18 \mathrm{~h}$. The mixture was then filtered, and the filtrate was used to determine $\mathrm{pH}$ value. The DM and WSC content and buffer capacity of alfalfa material were measured using the method described by Liu et al. [18]. Ground dried samples were used to determine monosaccharide contents (glucose, fructose, and xylose). Sugars in alfalfa were extracted with $80 \%$ ethanol and measured by Agilent HPLC 1260 equipped with a column (Skim-pack SCR-101C, Shimadzu, Inc. Japan) and refractive index detector [30]. The analytical column was performed at $85{ }^{\circ} \mathrm{C}$ using HPLC grade water as the mobile phase, with a flow rate of $1 \mathrm{~mL} / \mathrm{min}$. The fermentation coefficient (FC) of alfalfa silage was predicted according to the formula of Addah et al. [31], as follows: $\mathrm{FC}=\mathrm{DM} \%+8 \times \mathrm{WSC}$ g/ $/ \mathrm{kg} \mathrm{DM} \div \mathrm{BC} \mathrm{mEq} / \mathrm{kg} \mathrm{DM}$, where $\mathrm{BC}$ is the buffering capacity of the fresh alfalfa. FC expresses whether the fresh forage will ensile easily or will be difficult to ensile ( $\mathrm{FC}>45=$ easy, $\mathrm{FC}<35=$ difficult to ensile). The crude protein of alfalfa was analysed using the methods in AOAC-984.13 [32]. The contents of NDF and ADF of alfalfa material were measured using the method of Mertens et al. [33] and AOAC-973.18 [34], respectively. After silos were opened, the DM, WSC, sugars, crude protein, NDF, and ADF of the silage were measured by the same method used for the alfalfa material. The DM loss of the silage was estimated by measuring the differences in DM weights in the same silo after the silo was sealed for $2 \mathrm{~h}$ and after ensiling for 60 days. Corrected DM was calculated according to the formula of Porter et al. [35]. DM recovery was calculated by the formula: DM recovery $\%=(100-D M$ loss $) \%$. The filtrate was treated using the same approach as the alfalfa material and was used to measure the $\mathrm{pH}$ value, ammonia- $\mathrm{N}$ and organic acid content as in our previous study [28]. Fermentation quality was assessed by $\mathrm{V}$-score using the same method in our previous study [18].

\section{Data statistics and analyses}

An exponential decay model was used to fit the WSC and monosaccharide (glucose, fructose, and xylose) data using IBM Statistical Packages for the Social Sciences (IBM SPSS 20.0 for Windows) to describe the sugar change characteristics with the following equation:

$$
y=y 0+a * \exp (-b * x)
$$


where $y(\mathrm{~g} / \mathrm{kg} \mathrm{DM})$ is the residue at any time $x$ (day), $y 0(\mathrm{~g} / \mathrm{kg} \mathrm{DM})$ is the total residual fraction after 60 days of ensiling, $a(\mathrm{~g} / \mathrm{kg} \mathrm{DM})$ is the consumable fraction, $b$ $\left(\right.$ day $\left.^{-1}\right)$ is the fractional consumption rate of $a$ and $x$ is the ensilage time (day) [4].

The statistical analyses were performed using the IBM Statistical Packages for the Social Sciences (IBM SPSS 20.0 for Windows). The data were analysed by two-way analysis of variance (ANOVA, general linear models) (five treatments $\times$ four ensiling time $\times$ four replicates) to evaluate the effects of additives, ensiling time and their interaction on the fermentation characteristics, structural carbohydrate degradability and nonstructural carbohydrate fermentation of alfalfa silages. The data were analysed by one-way ANOVA (five treatments $\times$ four replicates) to evaluate the effects of additives on DM, DM recovery, $\mathrm{CP}$ and microbial composition of alfalfa silages after ensiling for 60 days. The means were then compared for significance using Tukey's test at $P<0.05$.

\section{Results}

Identification and enzyme expression level

\section{of recombinants}

Compared with the functional fragments of the reference genes (GenBank Accession No. M60178.1, U09580.1, M55080.1, and AB003694.1), there was no variation in the fusion genes usp 45-bgl1, usp 45-cbh2 and $u s p 45-e g l 3$, as exhibited by the $100 \%$ similarity to the sequence in GenBank. The positive transformants HT1/pMG36e-usp45-bgl1,

HT1/pMG36e-usp45cbh2 and HT1/pMG36e-usp45-egl3, degraded CMC, as demonstrated by the clear transparent zone, while HT1/pMG36e, HT1/pMG36e-bgl1, HT1/pMG36e-cbh2, and HT1/pMG36e-egl3 did not have clear transparent zones (Fig. 2). Furthermore, SDS-PAGE separately revealed an evident idio-strap of approximately $78 \mathrm{kDa}$ in HT1/pMG36e-usp45-bgl1, $50 \mathrm{kDa}$ in MG1363/pMG36eusp 45-cbh2 and $25 \mathrm{kDa}$ in HT1/pMG36e-usp 45-egl3 after culturing for $28 \mathrm{~h}$ compared with HT1/pMG36e in both the supernatant and cell samples (Fig. 3). The present study showed that the maximum extracellular endoglucanase expression level was $1118 \mathrm{mU} / \mathrm{mL}$ in L. lactis, which was higher than the expression levels of extracellular cellobiohydrolase $(222 \mathrm{mU} / \mathrm{mL})$ and $\beta$-glucosidase (131 mU/mL) (Fig. 4). In addition, HT2 showed high filter paper activity $(236 \mathrm{mU} / \mathrm{mL})$, which indicated that the combined recombinant $L$. lactis had a potential role in degrading lignocellulose.

\section{Changes in fermentation parameters in silages after ensiling}

The additives, ensiling time and their interaction significantly influenced $\mathrm{pH}$, lactic acid, acetic acid, the ratio of lactic acid to acetic acid (LA/AA), butyric acid, ammonia- $\mathrm{N}$ and $\mathrm{V}$-score $(P<0.05)$ (Table 2$)$. The lactic acid content in the control silage increased to $41.1 \mathrm{~g} / \mathrm{kg} D M$ during 18 days of ensiling but decreased to $16.3 \mathrm{~g} / \mathrm{kg} \mathrm{DM}$ at the final ensiling time (60 days), while the contents of acetic acid and ammonia- $\mathrm{N}$ in the control silage individually increased to $42.5 \mathrm{~g} / \mathrm{kg} \mathrm{DM}$ and $246 \mathrm{~g} / \mathrm{kg} \mathrm{N}$, respectively, during 60 days of ensiling. Under this condition of low LA/AA, the $\mathrm{pH}$ in the control silage decreased to 4.39 during 18 days of ensiling but increased to 5.35 after ensiling for 60 days. In addition, high butyric acid content was found in the control silage ( $36.94 \mathrm{~g} / \mathrm{kg} \mathrm{DM}$ ) after ensiling for 60 days, indicating poor quality (38.2 quality
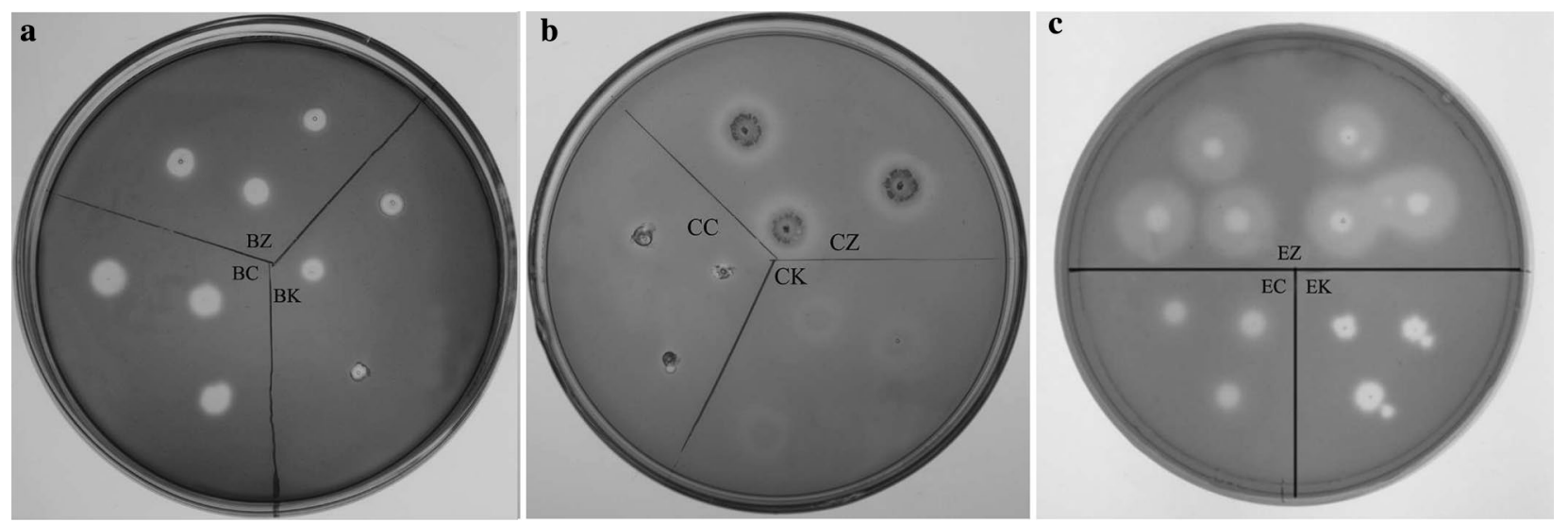

Fig. 2 Effects of recombinants expressing $\beta$-glucosidase, cellobiohydrolase and endoglucanase on the media containing sodium carboxymethylcellulose. a BC, L. lactis subsp. lactis MG1363/pMG36e; BK, L. lactis subsp. lactis MG1363/pMG36e-eg/3; BZ, L. lactis subsp. lactis MG1363/pMG36e-usp45-eg/3. b CC, L. lactis subsp. lactis MG1363/pMG36e; CK, L. lactis subsp. lactis MG1363/pMG36e-eg/3; CZ, L. lactis subsp. lactis MG1363/pMG36e-usp45-eg/3. c EC, L. lactis subsp. lactis MG1363/pMG36e; EK, L. lactis subsp. lactis MG1363/pMG36e-eg/3; EZ, L. lactis subsp. lactis MG1363/pMG36e-usp45-eg/3 


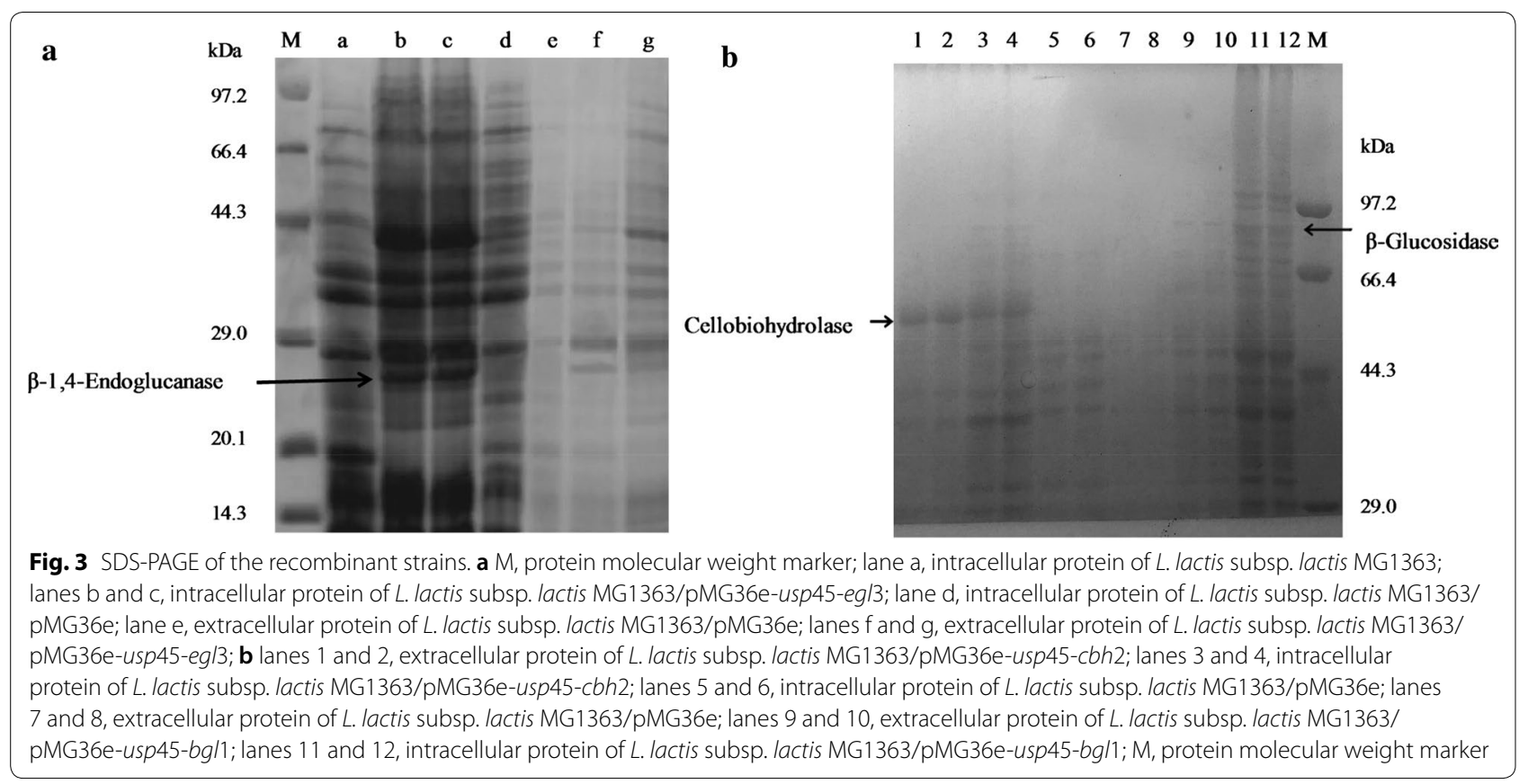

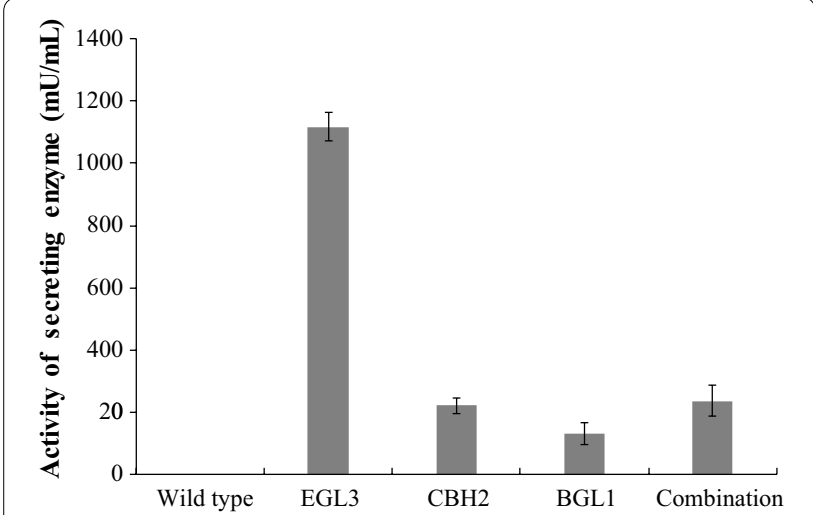

Fig. 4 The activities of secreting enzyme in each recombinant and their combination on degrading paper. $\mathrm{HT} 1$, wild-type L. lactis subsp. lactis MG1363; BGL1, HT1/pMG36e-usp45-bg/1; CBH2, HT1/ pMG36e-usp45-cbh2; EGL3, HT1/pMG36e-usp45-eg/3; combination, the mixed strains of $B G L 1, C B H 2$ and $E G L 3$

score). The HT1-treated silage had similar changes in $\mathrm{pH}$, lactic acid, acetic acid and butyric acid with the control silage during 60 days of ensiling $(P>0.05)$. Therefore, the HT1-treated silage had a poor-quality score (36.5). Compared with the control, EN, HT1 + EN and HT2 had better effects on increasing lactic acid content and decreasing ammonia- $\mathrm{N}$ content at each ensiling time $(P<0.05$ or $P>0.05)$. In addition, the EN-treated silage had higher acetic acid content $(P<0.05$ or $P>0.05)$, and the HT1+EN- and HT2-treated silages had lower acetic acid and ammonia- $\mathrm{N}$ content at each ensiling time $(P<0.05$ or $P>0.05)$. Therefore, lower $\mathrm{pH}$ values in the EN-, HT1+EN- and HT2-treated silages were observed compared to the control silage after ensiling for 60 days $(P<0.05)$, which eliminated butyric fermentation and improved the fermentation quality (quality score $>65$ ). However, HT1 + EN- and HT2-treated silage had higher lactic acid content and LA/AA $(P<0.05)$ and lower contents of acetic acid $(P<0.05)$ and ammonia- $\mathrm{N}(P>0.05)$ than EN-treated silage after ensiling for 60 days. Thus, the HT1 + EN- and HT2-treated silage obtained a higher quality score than the EN-treated silage (79.7 and 83.6 vs 68.8). No differences in the majority of fermentation quality parameters were found between $\mathrm{HT} 1+\mathrm{EN}$ and HT2 at most of the ensiling times $(P>0.05)$.

\section{Changes in structural carbohydrates in silages during ensiling}

The interaction of additive and ensiling time had a significant effect on most of the structural carbohydrates of alfalfa silages $(P<0.05)$, and ensiling time significantly influenced ADL $(P<0.05)$ (Fig. 5). All structural carbohydrates in the HT1-treated and control silages showed an increasing tendency during 60 days of ensiling. No differences in NDF, ADF, cellulose, hemicellulose and ADL were found between the control and additive treatments after ensiling for 1 day and 6 days $(P>0.05)$. In contrast, after ensiling for 18 and 60 days, compared with the control silages, the EN-, HT1 + EN- and HT2-treated silages had lower contents of NDF, ADF and cellulose $(P<0.05$ 
Table 2 Fermentative characteristics of high-moisture alfalfa silages after ensiling

\begin{tabular}{|c|c|c|c|c|c|c|c|c|c|}
\hline \multirow[t]{2}{*}{ Items } & \multirow[t]{2}{*}{ Additives } & \multicolumn{4}{|c|}{ Time (days) } & \multirow[t]{2}{*}{ SEM } & \multicolumn{3}{|c|}{ Significance } \\
\hline & & 1 & 6 & 18 & 60 & & Additives & Time & Additives $x$ time \\
\hline \multirow[t]{5}{*}{$\mathrm{pH}$} & Control & $5.80^{\mathrm{aA}}$ & $4.57^{\mathrm{aB}}$ & $4.39^{\mathrm{aB}}$ & $5.35^{\mathrm{aA}}$ & 0.059 & $<0.001$ & $<0.001$ & $<0.001$ \\
\hline & EN & $5.80^{\mathrm{aA}}$ & $4.42^{a b c}$ & $4.17^{\mathrm{bcD}}$ & $4.62^{\mathrm{bB}}$ & & & & \\
\hline & HT1 & $4.95^{\mathrm{CB}}$ & $4.42^{a b c}$ & $4.32^{a b c}$ & $5.22^{\mathrm{aA}}$ & & & & \\
\hline & $\mathrm{HT} 1+\mathrm{EN}$ & $5.23^{\mathrm{bA}}$ & $4.40^{a b B}$ & $4.29^{\mathrm{abcc}}$ & $4.47^{\mathrm{bB}}$ & & & & \\
\hline & HT2 & $4.76^{\mathrm{dA}}$ & $4.20^{b c}$ & $4.12^{\mathrm{cC}}$ & $4.49^{b B}$ & & & & \\
\hline \multirow[t]{5}{*}{ Lactic acid (g/kg DM) } & Control & $8.67^{\mathrm{bB}}$ & $40.1^{\mathrm{bA}}$ & $41.1^{\mathrm{bA}}$ & $16.3^{\mathrm{bB}}$ & 2.914 & $<0.001$ & $<0.001$ & $<0.001$ \\
\hline & EN & $10.3^{b c}$ & $45.2^{\mathrm{abAB}}$ & $56.6^{\mathrm{aA}}$ & $33.8^{\mathrm{bB}}$ & & & & \\
\hline & HT1 & $16.4^{\mathrm{aC}}$ & $40.3^{b B}$ & $49.4^{\mathrm{abA}}$ & $18.3^{b c}$ & & & & \\
\hline & $\mathrm{HT} 1+\mathrm{EN}$ & $16.1^{\mathrm{aC}}$ & $52.5^{\mathrm{aB}}$ & $50.1^{a b B}$ & $69.0^{\mathrm{aA}}$ & & & & \\
\hline & HT2 & $17.4^{\mathrm{aD}}$ & $41.9^{b c}$ & $58.2^{\mathrm{aB}}$ & $67.1^{\mathrm{aA}}$ & & & & \\
\hline \multirow[t]{5}{*}{ Acetic acid (g/kg DM) } & Control & $12.0^{\mathrm{aC}}$ & $22.8^{\mathrm{abBC}}$ & $32.4^{\mathrm{abAB}}$ & $42.5^{\mathrm{bA}}$ & 3.027 & $<0.001$ & $<0.001$ & $<0.001$ \\
\hline & EN & $12.2^{\mathrm{aC}}$ & $24.8^{\mathrm{aBC}}$ & $33.6^{\mathrm{aB}}$ & $79.2^{\mathrm{aA}}$ & & & & \\
\hline & HT1 & $2.10^{b c}$ & $16.0^{\mathrm{bcBC}}$ & $24.6^{\mathrm{bB}}$ & $46.2^{\mathrm{bA}}$ & & & & \\
\hline & $\mathrm{HT} 1+\mathrm{EN}$ & $5.09^{\mathrm{bD}}$ & $19.0^{\mathrm{abc}}$ & $30.9^{\mathrm{abB}}$ & $39.9^{\mathrm{bA}}$ & & & & \\
\hline & HT2 & $1.70^{\mathrm{bD}}$ & $9.56^{\mathrm{cC}}$ & $24.3^{b B}$ & $32.4^{\mathrm{bA}}$ & & & & \\
\hline \multirow[t]{5}{*}{ Propionic acid (g/kg DM) } & Control & 0.19 & 0.00 & 0.00 & 5.69 & 1.028 & 0.150 & 0.011 & 0.110 \\
\hline & EN & 0.00 & 0.00 & 0.00 & 0.00 & & & & \\
\hline & HT1 & $0.00^{B}$ & $0.00^{\mathrm{B}}$ & $0.00^{B}$ & $3.79^{\mathrm{A}}$ & & & & \\
\hline & $\mathrm{HT} 1+\mathrm{EN}$ & 0.00 & 0.00 & 0.00 & 0.00 & & & & \\
\hline & HT2 & 0.00 & 0.00 & 0.00 & 0.00 & & & & \\
\hline \multirow[t]{5}{*}{ Butyric acid (g/kg DM) } & Control & $0.00^{\mathrm{B}}$ & $0.00^{\mathrm{B}}$ & $0.59^{B}$ & $36.94^{\mathrm{aA}}$ & 2.700 & $<0.001$ & $<0.001$ & $<0.001$ \\
\hline & EN & 0.00 & 0.00 & 0.00 & 0.00 & & & & \\
\hline & HT1 & $0.00 \mathrm{~B}$ & $0.00 \mathrm{~B}$ & $0.00 \mathrm{~B}$ & $29.89^{\mathrm{aA}}$ & & & & \\
\hline & $\mathrm{HT} 1+\mathrm{EN}$ & 0.00 & 0.00 & 0.00 & $0.00^{b}$ & & & & \\
\hline & HT2 & 0.00 & 0.00 & 0.00 & $0.00^{b}$ & & & & \\
\hline \multirow[t]{5}{*}{ Ammonia-N (g/kg N) } & Control & $50.2^{\mathrm{aB}}$ & $103^{\mathrm{aB}}$ & $113^{\mathrm{aB}}$ & $246^{\mathrm{aA}}$ & 11.49 & $<0.001$ & $<0.001$ & $<0.001$ \\
\hline & EN & $48.2^{a b c}$ & $79.2^{b B}$ & $87.1^{\mathrm{bB}}$ & $129^{\mathrm{bA}}$ & & & & \\
\hline & HT1 & $35.6^{\mathrm{bcB}}$ & $65.8^{\mathrm{bcB}}$ & $83.26^{\mathrm{bB}}$ & $210^{\mathrm{abA}}$ & & & & \\
\hline & $\mathrm{HT} 1+\mathrm{EN}$ & $37.7^{\mathrm{abcD}}$ & $64.7^{\mathrm{bcc}}$ & $91.0^{\mathrm{bB}}$ & $108^{\mathrm{bA}}$ & & & & \\
\hline & HT2 & $34.0^{C D}$ & $51.9^{c C}$ & $81.1^{\mathrm{bB}}$ & $106^{\mathrm{bA}}$ & & & & \\
\hline \multirow[t]{5}{*}{ LA/AA } & Control & $0.74^{d B C}$ & $1.77^{\mathrm{bA}}$ & $1.26^{\mathrm{CAB}}$ & $0.38^{b c}$ & 0.254 & $<0.001$ & $<0.001$ & $<0.001$ \\
\hline & EN & $0.84^{\mathrm{dB}}$ & $1.83^{\mathrm{bA}}$ & $1.68^{\mathrm{bcAB}}$ & $0.44^{b c}$ & & & & \\
\hline & HT1 & $7.84^{\mathrm{bA}}$ & $2.64^{\mathrm{bB}}$ & $2.04^{\mathrm{abBC}}$ & $0.43^{b c}$ & & & & \\
\hline & $\mathrm{HT} 1$ + EN & $3.16^{\mathrm{CA}}$ & $2.81^{\mathrm{bA}}$ & $1.65^{\mathrm{bcB}}$ & $1.75^{\mathrm{aB}}$ & & & & \\
\hline & HT2 & $10.33 \mathrm{aA}$ & $4.40 \mathrm{aB}$ & $2.39 \mathrm{aC}$ & $2.08^{\mathrm{aC}}$ & & & & \\
\hline \multirow[t]{5}{*}{ V-score } & Control & $99.6^{\mathrm{abA}}$ & $85.9^{\mathrm{cA}}$ & $79.8^{\mathrm{bA}}$ & $38.2^{\mathrm{bcB}}$ & 2.519 & $<0.001$ & $<0.001$ & $<0.001$ \\
\hline & EN & $99.5^{\mathrm{bA}}$ & $91.7^{b B}$ & $87.9^{\mathrm{aB}}$ & $68.8^{\mathrm{abc}}$ & & & & \\
\hline & HT1 & $100^{\mathrm{aA}}$ & $95.6^{\mathrm{abAB}}$ & $88.8^{\mathrm{aB}}$ & $36.5^{c C}$ & & & & \\
\hline & HT1 + EN & $100^{\mathrm{aA}}$ & $95.4^{\mathrm{abA}}$ & $88.3^{\mathrm{aB}}$ & $79.7^{\mathrm{aC}}$ & & & & \\
\hline & HT2 & $100^{\mathrm{aA}}$ & $99.5^{\mathrm{aA}}$ & $91.7^{\mathrm{aB}}$ & $83.6^{\mathrm{aC}}$ & & & & \\
\hline
\end{tabular}

Values with different superscript lowercase letters show significant differences among treatments in the same ensiling day, values with different superscript capital letters show significant differences among ensiling days in the same treatment $(P<0.05)$ according to Tukey's test

Control, silage treated without additives; DM, dry matter; EN, cellulase; HT1, wild-type L. lactis subsp. lactis MG1363; HT1 + EN, combination of HT1 and EN; HT2, combination of transgenically engineered L. lactis strains HT1/pMG36e-usp45-bg/1, HT1/pMG36e-usp45-cbh2, and HT1/pMG36e-usp45-eg/3; N, nitrogen; LA/AA, ratio of lactic acid to acetic acid; SEM, standard error of the means 

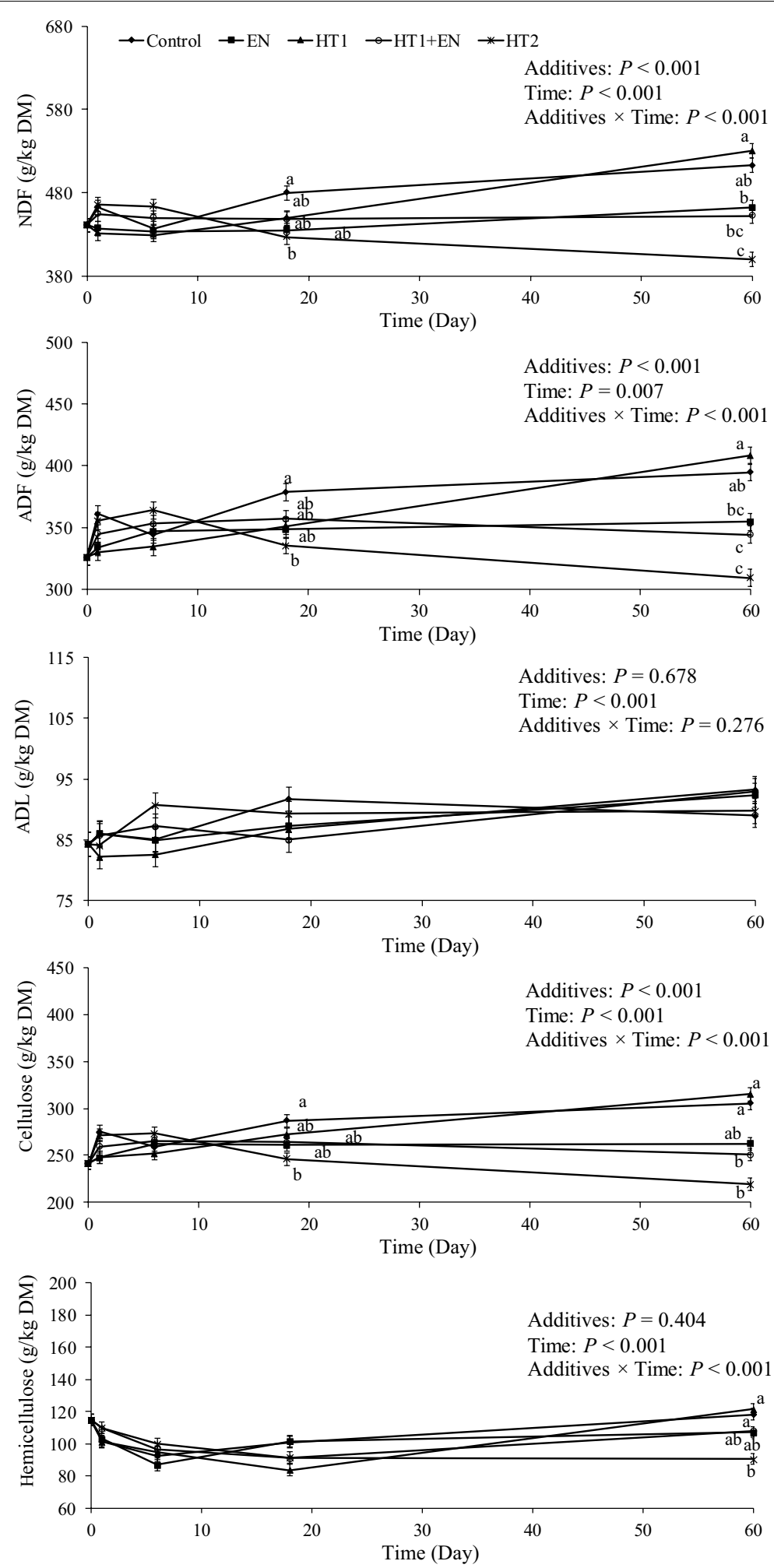

Fig. 5 Changes in NDF, ADF, ADL, cellulose and hemicellulose in alfalfa silages during ensiling for 60 days. Different lowercase letters (a-c) indicated difference at $P<0.05$ among additive treatments on the same ensiling day. Control, silage treated without additives; EN, cellulase; HT1, wild-type L. lactis subsp. lactis MG1363; HT1 + EN, combination of HT1 and EN; HT2, combination of transgenically engineered L. lactis strains HT1/pMG36e-usp45-bg/1, HT1/pMG36e-usp45-cbh2, and HT1/pMG36e-usp45-eg/3 
or $P>0.05)$. Furthermore, the HT2-treated silage had the lowest contents of NDF, ADF, cellulose and hemicellulose, followed by the HT1 + EN- and EN-treated silages after ensiling for 18 and 60 days $(P>0.05)$.

\section{Changes in nonstructural carbohydrates in silages during ensiling}

Additives, ensiling time and their interaction significantly influenced WSC and glucose, fructose and xylose $(P<0.05)$ (Fig. 6). As the ensiling time was prolonged to 60 days, nonstructural carbohydrates decreased $(P<0.05)$; in particular, glucose disappeared in all silages after ensiling for 18 days. After ensiling for 1 day, the HT1 + EN-treated silage had higher glucose than the control and the HT1-treated silage $(P<0.05)$ and had the highest fructose content $(P<0.05)$. However, EN, $\mathrm{HT} 1+\mathrm{EN}$ and HT2 increased the residual WSC, glucose, fructose, and xylose in silage compared with the control after ensiling for 6,18 and 60 days $(P<0.05$ or $P>0.05)$. Lower xylose content was found in the HT1-treated and control silages compared with the EN-, HT1+EN- and HT2-treated silages after ensiling for 60 days $(P<0.05)$. Furthermore, the HT2-treated silage had the highest WSC, xylose and fructose contents, followed by the HT1 + EN- and EN- treated silages $(P>0.05)$.

\section{Kinetic analysis of nonstructural carbohydrates in silages during ensiling}

The present study used a first-order exponential decay model to fit the measured data of nonstructural carbohydrates, and the kinetic parameters are shown in Table 3. Only WSC, glucose and fructose ( $R^{2}$ from 0.941 to 1$)$ were suitable to fit the model, since the correlation coefficients $\left(R^{2}\right.$ values) of the tested data approached 1 . The additives significantly influenced parameters of WSC, glucose and fructose $(P<0.05)$, except for the $b$ value in glucose $(P=0.054)$.

The $y 0$ values for WSC, glucose and fructose in the HT2-treated silage were the highest $(P<0.05$ or $P>0.05)$, indicating high residual sugars in the HT2-treated silage, while the $y 0$ values for WSC, glucose and fructose in the control silage were the lowest when compared with others $(P<0.05$ or $P>0.05)$. The HT2-treated silage had the lowest $a$ value for WSC, glucose and fructose when compared with others $(P<0.05$ or $P>0.05)$, indicated by the low consumable sugar fraction. The $b$ values for fructose in the EN-, HT1 + EN- and HT2-treated silages were lower than the control $(P<0.05)$, while the $b$ values for WSC in the EN-, HT1 + EN- and HT2-treated silages were higher than in the control $(P<0.05)$. Furthermore, the $b$ values for WSC and fructose in the HT1+ENtreated silage were lower than those in the HT2-treated silage $(P<0.05)$, as indicated by the lower sugar consumption rate in HT2-treated silage.

DM, DM recovery, crude protein and microbial composition of alfalfa silage after ensiling for $\mathbf{6 0}$ days

After ensiling for 60 days, additives markedly influenced DM, DM recovery, crude protein, and clostridium number $(P<0.05)$ (Fig. 7). The highest DM recovery, contents of DM and crude protein were found in the HT2-treated silage, followed by HT1+EN and EN $(P>0.05)$. In addition, compared with the control and HT1-treated silage, lower Clostridia spores were observed in HT2, HT1 + EN, and EN $(P<0.05)$.

\section{The effects of additives on the appearance evaluation of alfalfa silages}

After ensiling for 60 days, silages showed different shapes, colours, smells, and textures. The HT1 and control silage emitted an unpleasant odour and appeared black and sticky. There were no clear leaves in the HT1-treated and control silages. In contrast, the EN-, HT1 +EN-, and HT2-treated silages emitted a fragrance and were yellow but not sticky. The leaves were easily distinguished in the EN-, HT1 + EN-, and HT2-treated silages, indicating good process (see Additional file 1).

\section{Discussion}

pMG36e is known to be a constitutive expression vector for the inserted gene in L. lactis [36]. However, some reports have shown that the expression effect of some heterogeneous proteins appeared unstable [23, 37, 38], because the constitutive expression was correlated with the solubility of the heterogeneous protein [21]. In the present study, the active endoglucanase, cellobiohydrolase, and $\beta$-glucosidase of recombinant $L$. lactis were separately secreted into the culture medium, as indicated by correct folding and significant solubility.

The highest activities of the extracellular endoglucanase, cellobiohydrolase, and $\beta$-glucosidase in recombinant $L$. lactis were different, which demonstrated that the heterogeneous protein size and conformation were factors for heterologous protein secretion in L. lactis using usp 45 [21, 22]. In addition, the introduction of the large heterogeneous gene results in an oversized plasmid that increases metabolic load and accelerates cell death [39]. This might be the reason that the $b g l 1, c b h 2$, and $e g l 3$ genes were unable to be expressed together in L. lactis using usp 45 and pMG36e (unpublished data). Therefore, we had to separately express the $b g l 1, c b h 2$ and egl3 genes using usp 45 and pMG36e in L. lactis. Furthermore, after deleting the inherent sequence of the signal peptide in $b g l 1, c b h 2$ and egl3 and using usp 45 , an enhancement in secretion was promoted. One study 

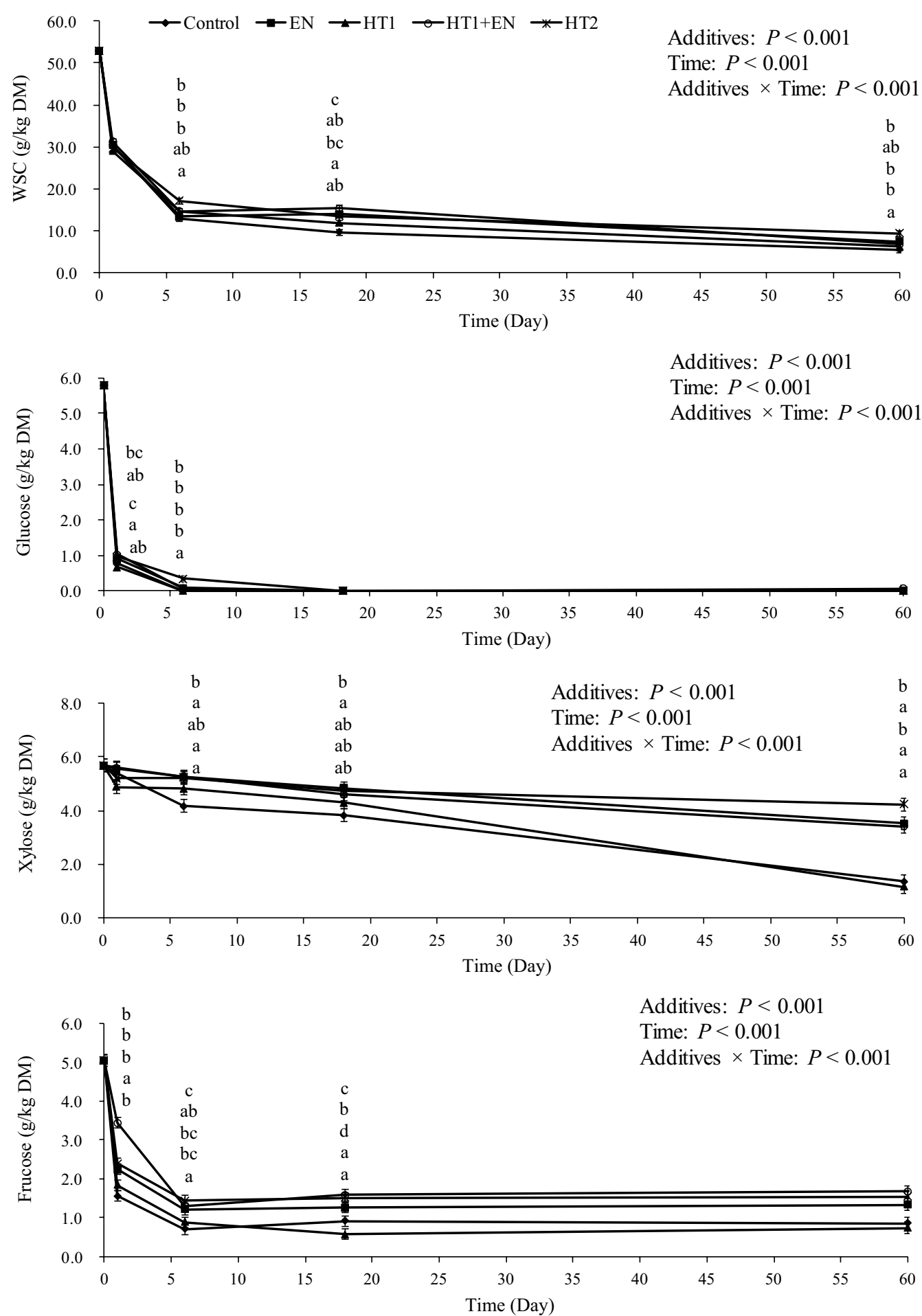

Fig. 6 Changes in WSC, glucose, xylose and fructose in alfalfa silages during ensiling for 60 days. Different lowercase letters (a-d, from top to bottom orderly corresponding to additive treatments) indicated difference at $P<0.05$ among additive treatments on the same ensiling day. WSC, water-soluble carbohydrates. Control, silage treated without additives; EN, cellulase; HT1, wild-type L. lactis subsp. lactis MG1363; HT1 + EN, combination of HT1 and EN; HT2, combination of transgenically engineered L. lactis strains HT1/pMG36e-usp45-bg/1, HT1/pMG36e-usp45-cbh2, and HT1/pMG36e-usp45-eg/3 
Table 3 Kinetic parameters of nonstructural carbohydrates reduction in alfalfa silages based on first-order exponential decay model $y=y 0+a^{*} e^{\left(-b^{*} x\right)}$

\begin{tabular}{|c|c|c|c|c|c|c|c|c|c|}
\hline \multirow[t]{2}{*}{ Additives } & \multicolumn{3}{|l|}{ wSC } & \multicolumn{3}{|l|}{ Glucose } & \multicolumn{3}{|c|}{ Fructose } \\
\hline & yo & $a$ & $b$ & yo & $a$ & $b$ & yo & $a$ & $b$ \\
\hline Control & $8.98^{e}$ & $43.6^{\mathrm{a}}$ & $0.69^{c}$ & $0.00^{b}$ & $5.81^{\mathrm{a}}$ & 1.99 & $0.84^{c}$ & $4.20^{b}$ & $1.67^{\mathrm{a}}$ \\
\hline EN & $11.4^{c}$ & $41.3^{c}$ & $0.77^{b}$ & $0.05^{b}$ & $5.76^{\mathrm{a}}$ & 1.77 & $1.28^{b}$ & $3.76^{c}$ & $1.33^{b}$ \\
\hline HT1 & $10.2^{d}$ & $42.3^{b}$ & $0.77^{\mathrm{b}}$ & $0.00^{b}$ & $5.81^{\mathrm{a}}$ & 2.00 & $0.73^{d}$ & $4.31^{\mathrm{a}}$ & $1.35^{b}$ \\
\hline $\mathrm{HT} 1+\mathrm{EN}$ & $12.0^{\mathrm{b}}$ & $40.6^{d}$ & $0.73^{b c}$ & $0.04^{b}$ & $5.77^{\mathrm{a}}$ & 1.75 & $1.50^{\mathrm{a}}$ & $3.56^{d}$ & $0.65^{c}$ \\
\hline HT2 & $13.2^{\mathrm{a}}$ & $39.5^{\mathrm{e}}$ & $0.85^{\mathrm{a}}$ & $0.13^{\mathrm{a}}$ & $5.64^{b}$ & 1.70 & $1.51^{\mathrm{a}}$ & $3.53^{d}$ & $1.35^{\mathrm{b}}$ \\
\hline SEM & 0.014 & 0.125 & 0.017 & 0.015 & 0.035 & 0.108 & 0.010 & 0.009 & 0.040 \\
\hline Significance & $<0.001$ & $<0.001$ & $<0.001$ & $<0.001$ & 0.004 & 0.054 & $<0.001$ & $<0.001$ & $<0.001$ \\
\hline
\end{tabular}

Means within a symbol with different superscript lowercase letters (a-e) differ $(P<0.05)$ according to Tukey's test

According to Li et al. [28], first-order exponential decay model was $y=y 0+a e^{\left(-b^{*}\right)}: y(\mathrm{~g} / \mathrm{kg} \mathrm{DM})$ is the residue at any time $x$ (day); $y 0$ (g/kg DM) is the total residual fraction after 60 days of ensiling; $a\left(\mathrm{~g} / \mathrm{kg} \mathrm{DM}\right.$ ) is the consumable fraction; $b\left(\right.$ day $\left.^{-1}\right)$ is the fractional consumption rate of $a$ and $x$ is the ensilage time (day)

$\mathrm{EN}$, cellulase; $\mathrm{HT} 1$, wild-type L. lactis subsp. lactis MG1363; $\mathrm{HT} 1$ + EN, combination of $\mathrm{HT} 1$ and $\mathrm{EN} ; \mathrm{HT} 2$, combination of transgenically engineered $L$. lactis strains HT1/pMG36e-usp45-bg/1, HT1/pMG36e-usp45-cbh2, and HT1/pMG36e-usp45-eg/3; SEM, standard error of the means

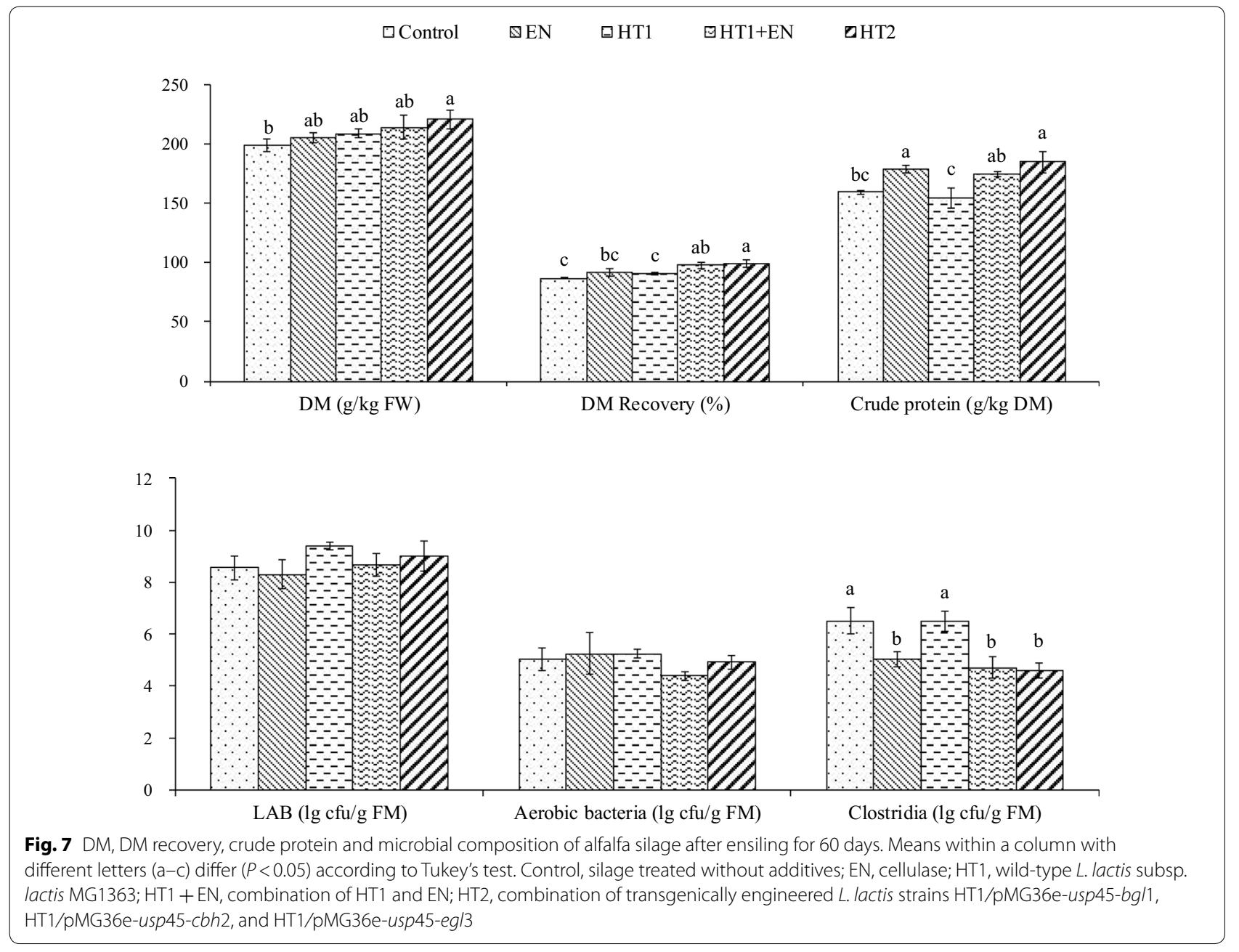


concluded that signal peptide and propeptide optimization could enhance secretion to increase heterologous protein production in L. lactis [21]. Additionally, the CMC activity of HT1/pMG36e-usp45-egl3 was higher than that of Clostridium thermocellum (1118 vs $140 \mathrm{mU} /$ $\mathrm{mL}$ ) and Bacillus subtilis $\mathrm{J12}$ (1118 vs $165 \mathrm{mU} / \mathrm{mL}$ ) [40, 41]. HT2 had higher filter paper activity than the average activity of cellulolytic rumen Enterococcus strains (236 vs $212 \mathrm{mU} / \mathrm{mL}$ ) and T. reesei (236 vs $190 \mathrm{mU} / \mathrm{mL}$ ) [4, 42]. These results indicated that the engineered L. lactis strains had stronger lignocellulose activities. The above outcomes could be attributed to the strategy for forming active cellulolytic proteins: (i) the intron and inherent sequence of the signal peptide in the $b g l 1, c b h 2$ and egl3 genes were deleted; and (ii) the sequences of the coding sequence in the $b g l 1, c b h 2$ and $e g l 3$ genes were separately fused with usp 45 .

The present study showed that lactic fermentation was not vigorous in the control silage after ensiling for 18 days, and as a result, insufficient lactic acid could not effectively decrease $\mathrm{pH}$ to prevent the emergence of Clostridia in the control silage. With an extended ensiling time of 60 days, vigorous butyric fermentation occurred, indicated by the poor fermentation quality of the control silage. This outcome could be caused by the low fermentation coefficient in high-moisture alfalfa, caused by low DM and WSC contents and high buffer capacity. Reports have concluded that high-moisture alfalfa is not easily fermented by epiphytic LAB, because it has low contents of DM and WSC and high buffer capacity [43, 44]. Similar to our previous studies [28], butyric fermentation led to high DM loss (low DM recovery), mainly in nutrient loss in the control silage. Markedly, protein degradation, considerable consumption of WSC and monosaccharides (glucose, fructose, and xylose), accumulation of ammonia- $\mathrm{N}$ and a sticky texture were observed in the control silage after ensiling for 60 days. Undoubtedly, many cell wall polysaccharides remained in the control silage. It has been suggested that measures should be used to well preserve high-moisture alfalfa well in the rainy season.

Cellulase has been used in ensiling bioprocesses because it degrades lignocellulose to provide sugars for LAB fermentation $[9,10]$. In the present study, the curves of structural carbohydrate degradation, WSC and monosaccharide consumption demonstrated that EN played a role in degrading lignocellulose to improve the fermentation quality of silage, which was the same as the outcomes in our previous studies $[17,18]$. However, the EN-treated silage did not exhibit vigorous lactic fermentation instead of acetic fermentation after ensiling for 60 days. These outcomes were explained by the high residual xylose derived from the degradation of lignocellulose, which stimulated heterolactic fermentation of the epiphytic $L A B$ of alfalfa during the final ensiling period. A similar result was reported by Lynch et al. who found acetic fermentation in cellulase-treated alfalfa silages after ensiling for 70 days, since the acetic acid content was close to or surpassed the lactic acid content [12].

Many researchers have focused on improving fermentation quality by inoculation with LAB $[18,45]$. The present study showed that HT1 promoted lactic fermentation during the first 18 days of ensiling, but did not eliminate butyric acid after ensiling for 60 days. This might be attributed to insufficient fermentative sugars for HT1 to produce lactic acid and restrain clostridial fermentation during a prolonged storage period. Similar to the control silage, the nutrient loss and cell wall polysaccharides increased in the HT1-treated silage. In addition, the sticky texture and unpleasant odour of the HT1-treated silage suggested that L. lactis could not ensile high-moisture alfalfa well in the rainy season. Kung reported that homofermentative LAB might lower silage $\mathrm{pH}$ relative to that in untreated silage, but the degree of reduction may or may not be sufficient to prevent clostridial growth, depending on the circumstances [46]. In the present study, low contents of DM and WSC and high buffer capacity in the ensiling material seriously limited the ability of HT1 to restrain clostridial fermentation.

Similar to previous studies [11, 17, 47], HT1+EN promoted lactic fermentation compared with untreated high-moisture alfalfa silage after ensiling for 18 and 60 days. This resulted from the dual function of HT1 + EN: (i) cellulase derived from T. reesei degraded lignocellulose into sugars well; and (ii) HT1 fermented sugars via homolactic fermentation. Compared with the HT1 inoculation, the HT1+EN inoculation did not enhance lactic fermentation after ensiling for 1 day but enhanced lactic fermentation after ensiling from 1 to 60 days. This indicated that, as long as HT1 was provided sufficient sugars that could be derived from cellulasedegrading lignocellulose, HT1 could restrain clostridial fermentation and improve the fermentation quality of high-moisture alfalfa silage when ensiling for prolonged periods of time. Compared with the EN-treated silage, the HT1 + EN-treated silage exhibited more vigorous lactic fermentation at the final ensiling time. This outcome did not verify that HT1 became the dominant species but it does suggest that HT1 had the ability to shift the inherent heterolactic fermentation into homolactic fermentation when the silage contained sufficient sugar. This was in contrast to the results of Lynch et al. [12], who found that inherent heterolactic fermentation in untreated alfalfa silage is difficult to change by adding cellulase combined with LAB after ensiling for 70 days. The inconsistent results from different studies were due to differences in the exogenous LAB inoculates. In the present 
study, L. lactis was a homofermentative LAB, while inoculates in the report of Lynch et al. contained heterofermentative LAB, Lactobacillus buchneri [12], which can degrade lactic acid to acetic acid, primarily after ensiling for 45 days [48].

HT2 considerably improved the fermentation quality of high-moisture alfalfa silage compared with the control silage in the present study. This was attributed to the fact that HT2 could secrete endoglucanase, cellobiohydrolase, and $\beta$-glucosidase to synergistically degrade lignocellulose into sufficient sugars utilizable by $L$. lactis to promote lactic fermentation. Similar results were found in the report of Li et al., who found that inoculation with a rumen Enterococcus strain resulted in the degradation of lignocellulose, which increased residual sugars, promoted lactic fermentation and preserved Pennisetum sinese silage as a biomass feedstock [4]. Compared with EN and HT1, the effect of promoting lactic fermentation and degrading lignocellulose into sugars was further enhanced after ensiling for 60 days. This outcome resulted from the dual function: HT2 secreted cellulase to degrade lignocellulose into sugars and promoted homolactic fermentation of itself. Moreover, HT2 degraded lignocellulose into more sugars utilizable by L. lactis, which not only enhanced fermentation of itself but also the high reserved sugars could benefit the subsequent biofuel production. A similar outcome was found in the report of Li et al., who found a high reserve of sugars in cellulolytic rumen Enterococcus strain-treated silage [4]. Kitamoto et al. reported that high preservation of soluble nonstructural carbohydrates deliver energy sources to microorganisms for maximally improving biofuel production, because they are apt to be converted into biofuel after the pretreatment process [6]. Moreover, HT2 had a lower consumption of sugars than HT1 + EN during 60 days of ensiling. According to the insignificant difference in the contents of lactic acid and acetic acid in HT2 and HT1+EN after ensiling for 60 days, it was inferred that HT2 had a better ability to convert sugar to acid. Furthermore, HT2 more strongly degraded lignocellulose to produce xylose compared with the control and other treatments, which was verified by the decrease in hemicellulose and high residual xylose content during ensiling from 18 to 60 days. Xylose became one of the main sugars (45.2\% in WSC) after prolonged ensiling, since xylose was hardly metabolized by the host L. lactis [49]. It can be inferred that the mechanism of hemicellulose degradation in the HT2-treated silage was enzymatic activity, acidolysis and microbial activity, which agreed with the outcome in the report of Dewar [50], who found that enzymolysis and acidolysis of hemicellulose after increasing nonstructural carbohydrates could occur effectively at a low $\mathrm{pH}$. Therefore, HT2 achieved the intended functions of a highly efficient degrading lignocellulose and well-ensiling high-moisture alfalfa silage as a biomass feedstock.

\section{Conclusions}

This is the first report in which engineered L. lactis strains with the $b g l 1, c b h 2$ and egl3 genes of $T$. reesei were successfully constructed and then extracellularly secreted endoglucanase, cellobiohydrolase and $\beta$-glucosidase. Ensiling experiments verified that the combination of transgenically engineered $L$. lactis strains ensiled highmoisture alfalfa silage efficiently, indicated by a lower $\mathrm{pH}$ and ammonia-N content, without butyric acid and a higher quality score compared with the untreated silage after ensiling for 60 days. The effects of transgenically engineered L. lactis strains on enhancing the conversion of lignocellulose to sugars were better than the combination of cellulase and wild-type $L$. lactis subsp. lactis MG1363, indicated by fewer structural carbohydrates and more available sugars in the silage treated with transgenically engineered $L$. lactis strains after ensiling for 60 days. Therefore, a new strategy for enhancing lignocellulosic degradation in high-moisture alfalfa was obtained by a bioprocess with transgenically engineered $L$. lactis strains, which could aid in the development of alfalfa as a biomass feedstock and promote second-generation biofuel development in the rainy season.

\section{Additional file}

Additional file 1. Images of silages after silo opening. Control, silage treated without additives; EN, cellulase; HT1, wild-type L. lactis subsp. lactis MG1363; HT1 + EN, combination of HT1 and EN; HT2, combination of transgenically engineered L. lactis strains HT1/pMG36e-usp45-bg/1, HT1/pMG36e-usp45-cbh2, and HT1/pMG36e-usp45-egl3.

\section{Abbreviations}

ADF: Acid detergent fibre; ADL: Acid detergent lignin; CMC: Carboxymethyl cellulose; Control: Silage treated without additives; DH5a: Escherichia coli DH5a; DM: Dry matter; EN: Cellulase; FC: Fermentation coefficient; FM: Fresh matter; HT1: Wild-type L. lactis subsp. lactis MG1363; HT1 + EN: Combination of $\mathrm{HT} 1$ and $\mathrm{EN}$; HT2: Combinati on of transgenically engineered L. lactis strains HT1/pMG36e-usp45-bg/1, HT1/pMG36e-usp45-cbh2, and HT1/pMG36e-usp45eg/3; LA/AA: Ratio of lactic acid to acetic acid; LAB: Lactic acid bacteria; N:

Nitrogen; NDF: Neutral detergent fibre; SDS-PAGE: Sodium dodecyl sulphatepolyacrylamide gel electrophoresis; SEM: Standard error of the means; usp45: Signal peptide of Usp45; WSC: Water-soluble carbohydrates.

\section{Authors' contributions}

QL performed all experiments and was a major contributor in writing the manuscript. All the authors read and approved the final manuscript.

\section{Acknowledgements}

Not applicable. 


\section{Competing interests}

The author declares that they have no competing interests about the overlapping extension PCR with Shanghai Generay Biotech Co., Ltd., Nanjing Genebay Biotech Co., Ltd. and others in the present study.

\section{Availability of data and materials}

Not applicable.

\section{Consent for publication}

Not applicable.

\section{Ethics approval and consent to participate}

Not applicable.

\section{Funds}

This work was supported by the National Key Research and Development Plan (Grant Number: 2017YFD0502106-1).

\section{Publisher's Note}

Springer Nature remains neutral with regard to jurisdictional claims in published maps and institutional affiliations.

Received: 15 December 2018 Accepted: 9 April 2019

Published online: 17 April 2019

\section{References}

1. Dien BS, Bothast RJ. A primer for lignocellulose biochemical conversion to fuel ethanol. In: Ingledew WM, editor. The alcohol textbook. Nottingham: Nottingham University Press; 2009. p. 73-94.

2. Dien BS, Miller DJ, Hector RE, Dixon RA, Chen F, McCaslin M, Reisen P, Sarath G, Cotta MA. Enhancing alfalfa conversion efficiencies for sugar recovery and ethanol production by altering lignin composition. Bioresour Technol. 2011;102:6479-86.

3. Gallagher D, Parker D, Allen DJ, Tsesmetzis N. Dynamic bacterial and fungal microbiomes during sweet sorghum ensiling impact bioethanol production. Bioresour Technol. 2018;264:163-73.

4. Li JF, Yuan XJ, Dong ZH, Mugabe W, Shao T. The effects of fibrolytic enzymes, cellulolytic fungi and bacteria on the fermentation characteristics, structural carbohydrates degradation, and enzymatic conversion yields of Pennisetum sinese silage. Bioresour Technol. 2018;264:123-30.

5. McDonald P, Henderson AR, Heron SJE. The Biochemistry of Silage, 1991.

6. Kitamoto HK, Horita M, Cai YM, Shinozaki Y, Sakaki K. Silage produces biofuel for local consumption. Biotechnol Biofuels. 2011;4:46.

7. Danner H, Holzer M, Mayrhuber E, Braun R. Acetic acid increases stability of silage under aerobic conditions. Appl Environ Microb. 2003;69:562-7.

8. Muck RE. Factors influencing silage quality and their implications for management. J Dairy Sci. 1988;71:2992-3002.

9. Dehghani MR, Weisbjerg MR, Hvelplund T, Kristensen NB. Effect of enzyme addition to forage at ensiling on silage chemical composition and NDF degradation characteristics. Livest Sci. 2012;150:51-8.

10. Sun QZ, Gao FQ, Yu Z, Tao Y, Zhao SF, Cai MY. Fermentation quality and chemical composition of shrub silage treated with lactic acid bacteria inoculants and cellulase additives. Anim Sci J. 2012;83:305-9.

11. Xing $L$, Chen $L$, Han $L$. The effect of an inoculant and enzymes on fermentation and nutritive value of sorghum straw silages. Bioresour Technol. 2009;100:488-91.

12. Lynch JP, Jin L, Lara EC, Baah J, Beauchemin KA. The effect of exogenous fibrolytic enzymes and a ferulic acid esterase-producing inoculant on the fibre degradability, chemical composition and conservation characteristics of alfalfa silage. Anim Feed Sci Tech. 2014;193:21-31.

13. Kozelov LK, Iliev F, Hristov AN, Zaman S, McAllister A. Effect of fibrolytic enzymes and an inoculant on in vitro digestibility and gas production of low-dry matter alfalfa silage. J Sci Food Agric. 2007;90:285.

14. Tarraran L, Mazzoli R. Alternative strategies for lignocellulose fermentation through lactic acid bacteria: the state of the art and perspectives. FEMS Microbiol Lett. 2018;365(15):fny126.

15. Stokes MR, Chen J. Effects of an enzyme-inoculant mixture on the course of fermentation of corn-silage. J Dairy Sci. 1994;77(11):3401-9.
16. Nakazawa H, Okada K, Kobayashi R, Kubota T, Onodera T, Ochiai N, Omata N, Ogasawara W, Okada H, Morikawa Y. Characterization of the catalytic domains of Trichoderma reesei endoglucanase I, II, and III, expressed in Escherichia coli. Appl Microbiol Biot. 2008;81:681-9.

17. Liu QH, Li XY, Desta ST, Zhang JG, Shao T. Effects of Lactobacillus plantarum and fibrolytic enzyme on the fermentation quality and in vitro digestibility of total mixed rations silage including rape straw. J Integr Agr. 2016;15:2087-96

18. Liu QH, Shao T, Bai YF. The effect of fibrolytic enzyme, Lactobacillus plantarum and two food antioxidants on the fermentation quality, alpha-tocopherol and beta-carotene of high moisture napier grass silage ensiled at different temperatures. Anim Feed Sci Tech. 2016;221:1-11.

19. Nakazawa H, Okada K, Onodera T, Ogasawara W, Okada H, Morikawa Y. Directed evolution of endoglucanase III (Cel12A) from Trichoderma reesei. Appl Microbiol Biot. 2009;83:649-57.

20. Liu QH, Shao T, Dong ZH, Bai YF. Solution for promoting eg/3 gene of Trichoderma reesei high-efficiency secretory expression in Escherichia coli and Lactococcus lactis. Process Biochem. 2017;62:135-43.

21. Le Loir Y, Nouaille S, Commissaire J, Bretigny L, Gruss A, Langella P. Signal peptide and propeptide optimization for heterologous protein secretion in Lactococcus lactis. Appl Environ Microb. 2001;67:4119-27.

22. Petitglatron MF, Monteil I, Benyahia F, Chambert R. Bacillus-Subtilis Levansucrase-amino-acid substitutions at one site affect secretion efficiency and refolding kinetics mediated by metals. Mol Microbiol. 1990:4:2063-70.

23. Kim SJ, Lee JY, Jun DY, Song JY, Lee WK, Cho MJ, Kim YH. Oral administration of Lactococcus lactis expressing Helicobacter pylori Cag7-ct383 protein induces systemic anti-Cag7 immune response in mice. Fems Immunol Med Mic. 2009;57:257-68.

24. Lambertz C, Garvey M, Klinger J, Heesel D, Klose H, Fischer R, Commandeur U. Challenges and advances in the heterologous expression of cellulolytic enzymes: a review. Biotechnol Biofuels. 2014;7:135.

25. Huff JP, Grant BJ, Penning CA, Sullivan KF. Optimization of routine transformation of Escherichia coli with plasmid DNA. Biotechniques. 1990;9(5):570-2.

26. Zheng M, Lin ZQ, Zeng WS. A practical electrotransformation method of Lactococcus lactis. Med Expl. 2018;2(1):18-24.

27. Mielenz JR. Biofuels methods and protocols. New York: Humana Press, Springer; 2009.

28. Liu QH, Dong ZH, Shao T. Effect of additives on fatty acid profile of high moisture alfalfa silage during ensiling and after exposure to air. Anim Feed Sci Tech. 2018;236:29-38.

29. Jonsson A. Enumeration and confirmation of clostridium-tyrobutyricum in silages using neutral red, D-cycloserine, and lactate-dehydrogenase activity. J Dairy Sci. 1990;73:719-25.

30. Zhao J, Dong ZH, Li JF, Chen L, Bai YF, Jia YS, Shao T. Ensiling as pretreatment of rice straw: the effect of hemicellulase and Lactobacillus plantarum on hemicellulose degradation and cellulose conversion. Bioresour Technol. 2018;266:158-65.

31. Addah W, Baah J, Groenewegen P, Okine EK, McAllister TA. Comparison of the fermentation characteristics, aerobic stability and nutritive value of barley and corn silages ensiled with or without a mixed bacterial inoculant. Can J Anim Sci. 2011:91:133-46.

32. AOAC-984.13. Protein (crude) in animal feed. Copper catalyst Kjeldahl method. In: Official methods of analysis of the association of official analytical chemists, 15th ed. Association of Official Analytical Chemistry. 1990. p. 74.

33. Mertens DR, Allen M, Carmany J, Clegg J, Davidowicz A, Drouches M, Frank K, Gambin D, Garkie M, Gildemeister B, Jeffress D, Jeon CS, Jones D, Kaplan D, Kim GN, Kobata S, Main D, Moua X, Paul B, Robertson J, Taysom D, Thiex N, Williams J, Wolf M. Gravimetric determination of amylasetreated neutral detergent fiber in feeds with refluxing in beakers or crucibles: collaborative study. J AOAC Int. 2002;85:1217-40.

34. AOAC. Official methods of analysis, 18th ed. AOAC Int., Gaithersburg, MD., 2005.

35. Porter MG, Steen RWJ, Kilpatrick DJ, Gordon FJ, Mayne CS, Poots RE, Unsworth EF, Pippard CJ. Electrometric titration as a method of predicting the chemical composition and corrected dry matter concentration of silage. Anim Feed Sci Tech. 1995;56:217-30. 
36. Vandeguchte M, Vandervossen JMBM, Kok J, Venema G. Construction of a lactococcal expression vector-expression of hen egg-white lysozyme in Lactococcus lactis subsp lactis. Appl Environ Microb. 1989;55:224-8.

37. Kim SJ, Jun DY, Yang CH, Kim YH. Expression of Helicobacter pylori cag12 gene in Lactococcus lactis MG1363 and its oral administration to induce systemic anti-Cag12 immune response in mice. Appl Microbiol Biot 2006:72:462-70

38. Kim SJ, Jun DY, Yang CH, Kim YH. Cloning and expression of hpaA gene of Korean strain Helicobacter pylori K51 in oral vaccine delivery vehicle Lactococcus lactis subsp lactis MG1363. J Microbiol Biotechnol. 2006;16:318-24.

39. Glick D. Metabolic load and heterologous gene expression. Biotech Adv. 1985;13:247.

40. Kuancha C, Sukklang S, Detvisitsakun C, Chanton S, Apiraksakorn J. Fermentable sugars production from lignocellulosic materials hydrolysis by thermophilic enzymes from, Bacillus subtilis J12. Energy Procedia. 2017;138:151-6.

41. Zverlov W, Schwarz WH. Bacterial cellulose hydrolysis in anaerobic environmental subsystems-Clostridium thermocellum and Clostridium stercorarium, thermophilic plant-fiber degraders. Ann NY Acad Sci. 2008:1125:298-307.

42. Mukhopadhyay S, Nandi B. Optimization of cellulase production by Trichoderma reesei ATCC 26921 using a simplified medium on water hyacinth biomass. J Sci Ind Res India. 1999;58:107-11.

43. Owens VN, Albrecht KA, Muck RE, Duke SH. Protein degradation and fermentation characteristics of red clover and alfalfa silage harvested with varying levels of total nonstructural carbohydrates. Crop Sci. 1999;39:1873-80.

44. Ke WC, Yang FY, Undersander DJ, Guo XS. Fermentation characteristics, aerobic stability, proteolysis and lipid composition of alfalfa silage ensiled with apple or grape pomace. Anim Feed Sci Tech. 2015;202:12-9.

45. Nkosi BD, Meeske R, Palic D, Langa T. Laboratory evaluation of an inoculant for ensiling whole crop maize in South Africa. Anim Feed Sci Tech. 2009;150:144-50.

46. Kung L, Muck RE. Silage additives: where are we going? In: Proceedings of the XVII international silage conference, July 1-3., Piracicaba, São Paulo. 2015. p. 72-81.

47. Nadeau EMG, Buxton DR, Russell JR, Allison MJ, Young JW. Enzyme, bacterial inoculant, and formic acid effects on silage composition of orchardgrass and alfalfa. J Dairy Sci. 2000;83:1487-502.

48. Muck RE, Nadeau EMG, McAllister TA, Contreras-Govea FE, Santos MC, Kung $L$. Silage review: recent advances and future uses of silage additives. J Dairy Sci. 2018;101:3980-4000.

49. Erlandson KA, Park JH, El Khal W, Kao HH, Basaran P, Brydges S, Batt CA. Dissolution of xylose metabolism in Lactococcus lactis. Appl Environ Microb. 2000;66:3974-80.

50. Dewar WA, Mcdonald P, Whittenbury R. The hydrolysis of grass hemicelluloses during ensilage. J Sci Food Agric. 1963;14:411-7.
Ready to submit your research? Choose BMC and benefit from:

- fast, convenient online submission

- thorough peer review by experienced researchers in your field

- rapid publication on acceptance

- support for research data, including large and complex data types

- gold Open Access which fosters wider collaboration and increased citations

- maximum visibility for your research: over 100M website views per year

At BMC, research is always in progress.

Learn more biomedcentral.com/submissions 